\title{
A Novel Antagonist Peptide Reveals a Physiological Role of Insulin-Like Peptide 5 in Control of Colorectal Function
}

\author{
Ruslan V Pustovit ${ }^{\dagger, \pi, \Delta}$, Xiaozhou Zhang ${ }^{\dagger, \pi}$, Jamie JM Liew ${ }^{\dagger}$, Praveen \\ Praveen ${ }^{\dagger}$, Mengjie Liu ${ }^{\dagger}$, Ada $\mathrm{Koo}^{\Delta}$, Lalita Oparija-Rogenmozere ${ }^{\dagger}$, \\ Qinghao $\mathrm{Ou}^{\dagger}$, Martina Kocan ${ }^{\dagger, \alpha}$, Shuai $\mathrm{Nie}^{\delta}$, Ross AD Bathgate $^{\dagger, \S}$, John \\ B Furness ${ }^{\dagger, \Delta, \#}$ and Mohammed Akhter Hossain ${ }^{\dagger, \zeta, \#, *}$
}

†The Florey Institute of Neuroscience and Mental Health; ${ }^{\Delta}$ Department of Anatomy and Physiology;

${ }^{\alpha}$ School of Biosciences, ${ }^{\delta}$ Melbourne Mass Spectrometry and Proteomics Facility, Bio21 Institute; $\S$ Department of Biochemistry and Pharmacology; `School of Chemistry; The University of Melbourne, Victoria 3052, Australia.

TEqual first authors: Ruslan V Pustovit and Xiaozhou Zhang

\#Equal senior authors: John B Furness and Mohammed Akhter Hossain

\begin{abstract}
*Corresponding Author
Mohammed Akhter Hossain

The Florey Institute of Neuroscience and Mental Health and Department of Chemistry,

University of Melbourne
\end{abstract}

Parkville, VIC 3052

Australia

Email: akhter.hossain@unimelb.edu.au 


\section{Table of Contents}

1. COMPARISON OF THE ACTIVITY OF R3/I5 IN CHO CELLS EXPRESSING HUMAN RXFP4 OR NANOLUCIFERASE TAGGED HRXFP4.

2. ANALYTICAL RP-HPLC AND ESI-MS OF ALL FINAL COMPOUNDS. 3

2.1 INSL5-A13HR 3

2.2 INSL5-A13NR .4

2.3 INSL5-A13AGP 4

3 TABLE S1: SUMMARY OF PEPTIDE CHARACTERIZATION BY ESI-MS AND HPLC. 4 4 PEPTIDE CONTENT . .4

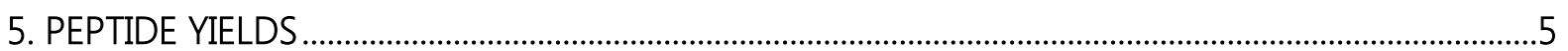

6. PHARMACOKINETICS - Sample preparation and Mass spectrometry.................................................5

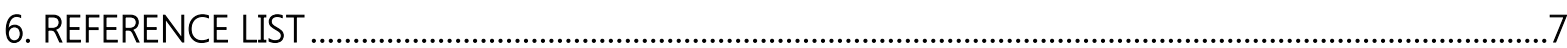




\section{Figure S1}

Comparison of the activity of R3/I5 on the inhibition of forskolin-induced cAMP activation in CHO cells expressing human RXFP4 (hRXFP4) or Nanoluciferase tagged hRXFP4 (hRXFP4-Nluc). Pooled mean \pm SEM data from 5 independent experiments with triplicate determinations in each assay.

\section{R3/I5-induced cAMP inhibition}

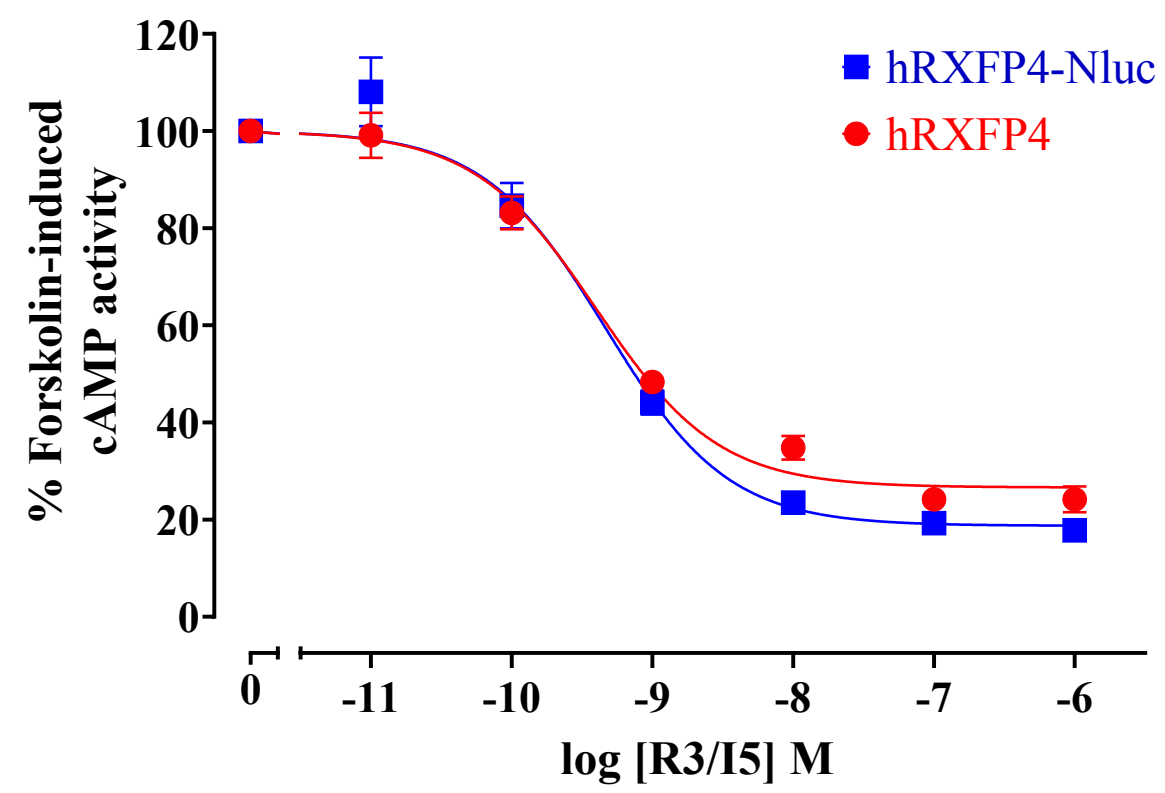

\section{Analytical RP-HPLC and ESI-MS of all final compounds}

Analytical RP-HPLC analysis of the purified compounds was performed with Waters RP- HPLC systems using Empower software for data collection, monitoring and analysis. The RP- HPLC profiles were acquired using a Phenomenex Gemini C18 analytical column ( 4.6 x $250 \mathrm{~mm}$, pore size $300 \AA$, particle size $5 \mu \mathrm{m}$ ), at a constant flow rate of $1.5 \mathrm{~mL} / \mathrm{min}$, in a gradient mode with buffer A: $0.1 \%$ aq. TFA and buffer B: $0.1 \%$ TFA in acetonitrile, monitoring at a wavelength of $214 \mathrm{~nm}$ which is characteristic for the amide bond.

ESI-MS spectra were carried out on a Thermo Exactive Plus Orbitrap mass spectrometer (Thermo Fisher Scientific, San Jose, CA, USA). Methods used for mass was 400 to $4000 \mathrm{~m} / \mathrm{z}$ in positive-ion mode.

\subsection{INSL5-A13HR}

RP-HPLC carried out as described above using the elution gradient: buffer B 20-50\% over 30 minutes, tR $22.544 \mathrm{~min}$.

ESI-MS m/z calculated 4270.97, observed 4270.0708

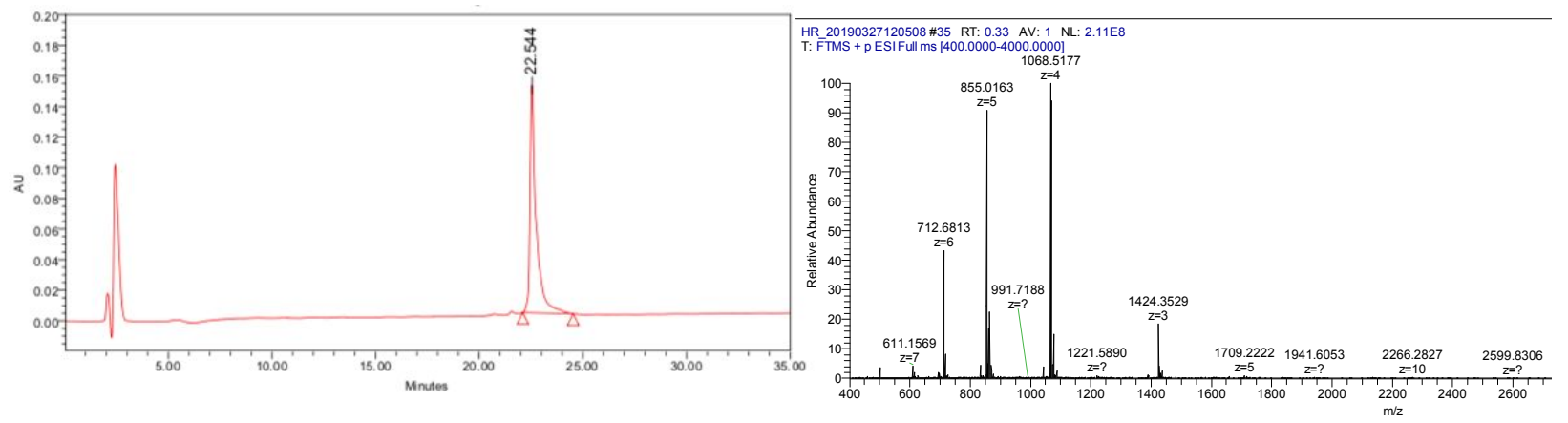

Figure S2.1 RP-HPLC profile of INSL5-A13HR (left) and ESI-MS (right) 


\subsection{INSL5-A13NR}

RP-HPLC carried out as described above using the elution gradient: buffer B 20-50\% over 30 minutes, tR $23.567 \mathrm{~min}$.

ESI-MS m/z calculated 4242.97, observed 4242.0644
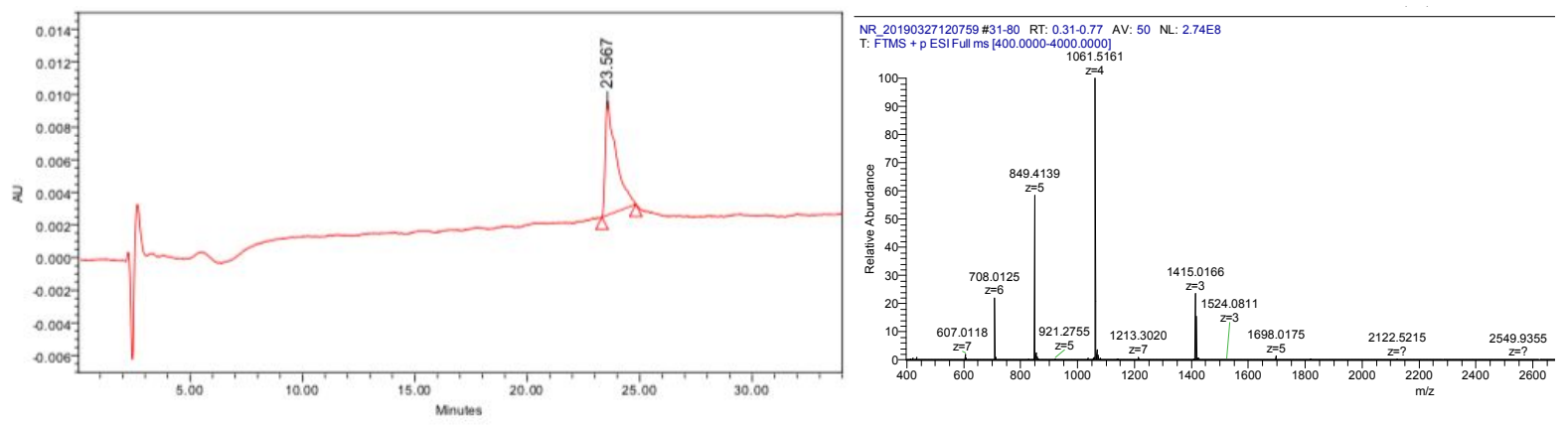

Figure S2.2 RP-HPLC profile of INSL5-A13HR (left) and ESI-MS (right)

\subsection{INSL5-A13Agp}

RP-HPLC carried out as described above using the elution gradient: buffer B 20-50\% over 30 minutes, tR $23.031 \mathrm{~min}$.

ESI-MS m/z calculated 4228.97, observed 4228.048
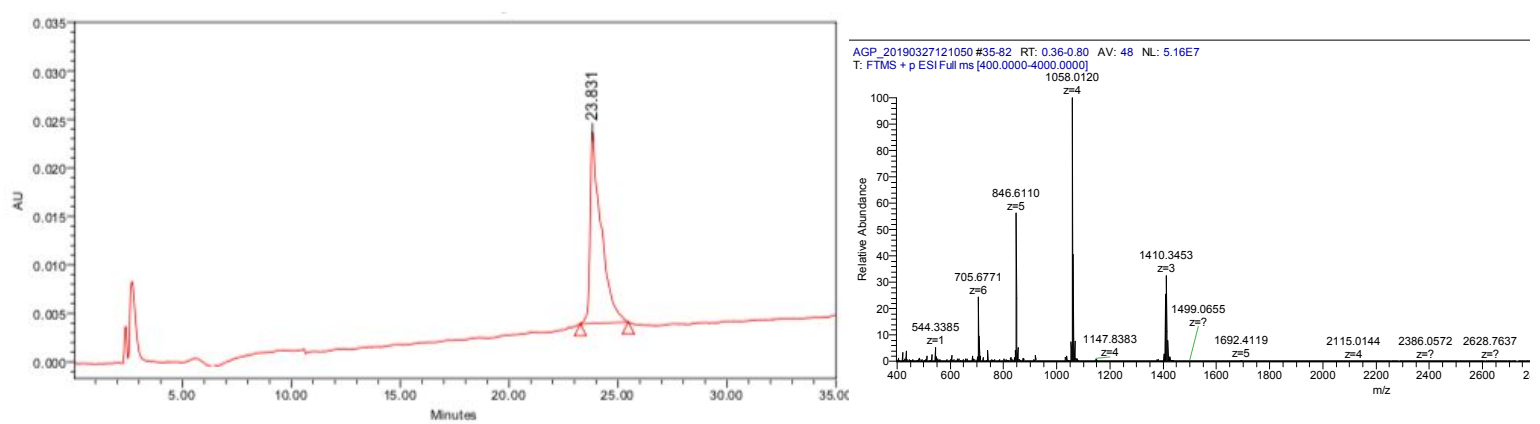

Figure S2.3 RP-HPLC profile of INSL5-A13Agp (left) and ESI-MS (right)

3 Table S1: Summary of peptide characterization by ESI-MS and HPLC

\begin{tabular}{|l|c|c|c|c|c|c|c|}
\hline \multirow{2}{*}{$\begin{array}{c}\text { INSL5 } \\
\text { analogues }\end{array}$} & \multicolumn{2}{|c|}{ ESI-MS } & \multicolumn{3}{c|}{ HPLC } & Purity(\%) & $\begin{array}{c}\text { Yield } \\
(\%)\end{array}$ \\
\cline { 2 - 8 } & Observed1 & calculated & $\begin{array}{c}\text { TR } \\
\text { (min) }\end{array}$ & $\begin{array}{c}\text { T0 } \\
\text { (min) }\end{array}$ & $\begin{array}{c}\mathrm{K}^{\prime} \\
\text { (tR- } \\
\text { T0)/tR }\end{array}$ & & \\
\hline INSL5-A13HR & 4270.0708 & 4270.97 & 22.544 & 2.441 & 0.892 & 99.27 & 11.59 \\
\hline INSL5-A13NR & 4242.0644 & 4242.97 & 23.567 & 2.679 & 0.886 & 100 & 5.97 \\
\hline INSL5-A13Agp & 4228.048 & 4228.97 & 23.031 & 2.661 & 0.884 & 99.92 & 8.88 \\
\hline
\end{tabular}

${ }^{1}$ Observed molecular weights were determined by ESI-MS of the purified peptides

${ }^{2}$ HPLC analysis was performed as specified in section 1 of this Supporting Information 


\section{Peptide content determination}

The peptide contents for INSL5-A13HR, INSL5-A13NR, and INSL5-A13Agp were determined using Direct detect assay-free sample cards and the Direct Detect spectrometer. Each card contains hydrophilic spots surrounded by a hydrophobic ring to retain the analyzed sample within the IR beam for convenient sample application and analysis. All measurements were performed using $2 \mu \mathrm{L}$ of sample solution.

\begin{tabular}{|l|l|}
\hline INSL5 analogues & Peptide content (\%) \\
\hline INSL5-A13HR & $100 \%$ \\
\hline INSL5-A13NR & $70 \%$ \\
\hline INSL5-A13Agp & $100 \%$ \\
\hline
\end{tabular}

Table S2: Summary of peptide content by Direct detect

\section{Peptide yields}

The A and B-chains of respective peptides were separately synthesized using standard SPPS protocols ${ }^{11}$. The A-chains were conjugated to their respective B-chain using our protocol resulting in INSL5-A13HR (Yield 11.59\%), INSL5-A13NR (Yield 5.97\%), INSL5-A13Agp (Yield 8.88\%). The yield was calculated from the purified B-chains as starting material. The synthesis of these peptides is shown in Scheme S1.

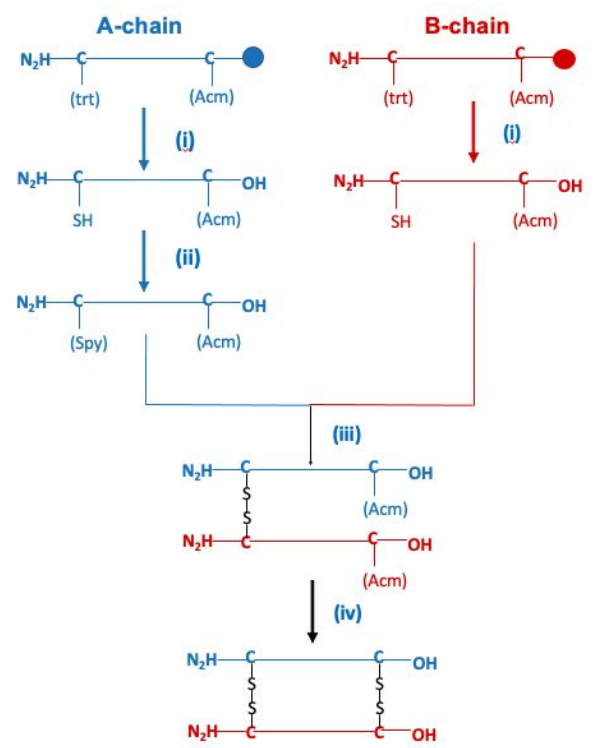

Scheme S1: The general schematic flowchart of peptide synthesis.

\section{Pharmacokinetics - Sample preparation and Mass spectrometry}

Standard and sample preparation for mass spectrometry

Calibration curve was prepared by spiking a pre-determined concentration of peptide standard in blank plasma prior to sample processing. $70 \mu \mathrm{L}$ of $8 \mathrm{M}$ urea (prepared in $50 \mathrm{mM} \mathrm{TEAB}, \mathrm{pH}$ 8) was added to $30 \mu \mathrm{L}$ of plasma. Samples were sonicated at $37^{\circ} \mathrm{C}$ for 30 minutes then TCEP was added at a final concentration of $10 \mathrm{mM}$ and incubated at $37^{\circ} \mathrm{C}$ for 45 minutes on shaker. Freshly prepared IAA in $25 \mathrm{mM}$ TEAB was then added at a final concentration of $55 \mathrm{mM}$ and incubated at $37^{\circ} \mathrm{C}$ for 45 minutes on shaker in the dark. $25 \mathrm{mM}$ TEAB was added to each sample to get a total volume of $800 \mu \mathrm{L}$ to dilute the urea to less than $1 \mathrm{M}$. A $50 \mu \mathrm{L}$ aliquot was taken from each sample and transferred to a new LoBind $®$ tube, $1 \mu \mathrm{g}$ of trypsin was added to each aliquot and incubated at $37^{\circ} \mathrm{C}$ overnight. Samples were acidified by adding formic acid to a final concentration of $1 \%$. Samples were desalted using the Oasis ${ }^{\circledR}$ HLB 1 cc $(10 \mathrm{mg})$ Extraction Cartridge (Waters, Rydalmere NSW, Australia). Peptides were eluted in $80 \%$ acetonitrile containing $0.1 \%$ TFA into LoBind ${ }^{\circledR}$ tubes. Sample volume was reduced to $\leq 160$ 
$\mu \mathrm{L}$ (removing volume of acetonitrile) using SpeedVac vacuum concentrator. Samples were lyophilized in freeze dryer overnight then resuspended in $2 \%$ acetonitrile with $0.05 \%$ TFA for LC/MS analysis.

LC-MS/MS analysis

Peptide samples were analysed by liquid chromatography coupled with tandem mass spectrometry (LC-MS/MS) using an Exploris 480 Orbitrap mass spectrometer coupled to an Ultimate 3000 UHPLC (Thermo Fisher Scientific, San Jose, CA). Solvent A is $0.1 \%$ formic acid (FA) / $5 \%$ dimethyl sulfoxide (DMSO) in water and solvent B is $0.1 \%$ FA / 5\% DMSO in acetonitrile (ACN). Each sample was injected onto a PepMap C18 trap column (75 $\mu$ M X $2 \mathrm{~cm}$, $3 \mu \mathrm{M}, 100$ Å, Thermo Fisher Scientific, San Jose, CA) at $6 \mu \mathrm{L} / \mathrm{min}$ for $6 \mathrm{~min}$ using $0.05 \%$ trifluoroacetic acid (TFA) / 3\% ACN in water and then separated through a PepMap C18 analytical column $(75 \mu \mathrm{M} \mathrm{X} 50 \mathrm{~cm}, 2 \mu \mathrm{M}, 100 \AA$, Thermo Fisher Scientific, San Jose, CA) at a flow rate of $300 \mathrm{~nL} / \mathrm{min}$. The temperature of both columns was maintained at $50{ }^{\circ} \mathrm{C}$. During separation, the percentage of solvent B in mobile phase was increased from $3 \%$ to $25 \%$ in $22 \mathrm{~min}$, from $25 \%$ to $40 \%$ in $2 \mathrm{~min}$ and from $40 \%$ to $85 \%$ in $2 \mathrm{~min}$. Then the columns were cleaned at $85 \%$ solvent B for $2 \mathrm{~min}$ before decreasing the $\%$ B to $3 \%$ in $0.1 \mathrm{~min}$ and re-equilibrating for $10.9 \mathrm{~min}$. The spray voltage, temperature of ion transfer tube and radio frequency (RF) lens of the Exploris 480 Orbitrap mass spectrometer were set at $1.9 \mathrm{kV}, 275{ }^{\circ} \mathrm{C}$ and $30 \%$, respectively. The full MS scans were acquired at $\mathrm{m} / \mathrm{z} 300$ 1600 , a resolving power of 60,000 at $\mathrm{m} / \mathrm{z} 200$, a normalized auto gain control (AGC) target at $300 \%$ and a maximum injection time of 25 milliseconds (ms). After each full MS scan, a targeted higher-energy collisional dissociation (HCD)-MS/MS was performed at a normalized AGC target of 300\%, a maximum injection time of $100 \mathrm{~ms}$, an isolation window of $\mathrm{m} / \mathrm{z}$ 4, a normalized collision energy (NCE) of $30 \%$ and a mass resolution of 15,000 at $\mathrm{m} / \mathrm{z} 200$ for ions at m/z 512.2682 ( $\mathrm{z}=2$ ) from LC(carbamidomethyl)GLEYIR. The peak area of $\mathrm{y}_{6}$ fragment ion at $\mathrm{m} / \mathrm{z}=750.4145(\mathrm{z}=1)$ was monitored using Skyline (20.2.0) for quantitative analysis. 


\section{Reference list}

1. Hossain, M. A.; Bathgate, R. A.; Kong, C. K.; Shabanpoor, F.; Zhang, S.; Haugaard-Jonsson, L. M.; Rosengren, K. J.; Tregear, G. W.; Wade, J. D., Synthesis, conformation, and activity of human insulin-like peptide 5 (INSL5). Chembiochem 2008, 9 (11), 1816-1822. doi: 10.1002/cbic.200800113.

2. $\quad$ Patil, N. A.; Hughes, R. A.; Rosengren, K. J.; Kocan, M.; Ang, S. Y.; Tailhades, J.; Separovic, F.; Summers, R. J.; Grosse, J.; Wade, J. D.; Bathgate, R. A.; Hossain, M. A., Engineering of a novel simplified human insulin-like peptide 5 agonist. J Med Chem 2016, 59 (5), 2118-2125. doi: 10.1021/acs.jmedchem.5b01786.

3. Shabanpoor, F.; Hughes, R. A.; Bathgate, R. A.; Zhang, S.; Scanlon, D. B.; Lin, F.; Hossain, M. A.; Separovic, F.; Wade, J. D., Solid-phase synthesis of europium-labeled human INSL3 as a novel probe for the study of ligand-receptor interactions. Bioconjug Chem 2008, 19 (7), 1456-1463. doi: 10.1021/bc800127p.

4. $\quad$ Belgi, A.; Bathgate, R. A.; Kocan, M.; Patil, N.; Zhang, S.; Tregear, G. W.; Wade, J. D.; Hossain, M. A., Minimum active structure of insulin-like peptide 5. J Med Chem 2013, 56 (23), 9509-9516. doi: 10.1021/jm400924p.

5. Belgi, A.; Bathgate, R. A.; Tregear, G. W.; Wade, J. D.; Hossain, M. A., Preliminary structure-function relationship studies on insulin-like peptide 5 (INSL5). Int J Pept Res Ther 2013, 19, 71-79. doi: 10.1007/s10989013-9341-4.

6. Ang, S. Y.; Hutchinson, D. S.; Patil, N.; Evans, B. A.; Bathgate, R. A.; Halls, M. L.; Hossain, M. A.; Summers, R. J.; Kocan, M., Signal transduction pathways activated by insulin-like peptide 5 at the relaxin family peptide RXFP4 receptor. Br J Pharmacol 2016, 174(10):1077-1089 doi: 10.1111/bph.13522.

7. Kocan, M.; See, H. B.; Seeber, R. M.; Eidne, K. A.; Pfleger, K. D., Demonstration of improvements to the bioluminescence resonance energy transfer (BRET) technology for the monitoring of G protein-coupled receptors in live cells. J Biomol Screen 2008, 13 (9), 888-898. doi: 10.1177/1087057108324032.

8. $\quad$ Hatzipantelis, C. J.; Lu, Y.; Spark, D. L.; Langmead, C. J.; Stewart, G. D., beta-Arrestin-2-Dependent Mechanism of GPR52 Signaling in Frontal Cortical Neurons. ACS Chem Neurosci 2020, 11 (14), 2077-2084. doi: doi: 10.1021/acschemneuro.0c00199.

9. Grosse, J.; Heffron, H.; Burling, K.; Hossain, M. A.; Habib, A. M.; Rogers, G. J.; Richards, P.; Larder, R.; Rimmington, D.; Adriaenssens, A. A.; Parton, L.; Powell, J.; Binda, M.; Colledge, W. H.; Doran, J.; Toyoda, Y.; Wade, J. D.; Aparicio, S.; Carlton, M. B.; Coll, A. P.; Reimann, F.; O'Rahilly, S.; Gribble, F. M., Insulin-like peptide 5 is an orexigenic gastrointestinal hormone. Proc Natl Acad Sci U S A 2014, 111 (30), 11133-11138. doi: 10.1073/pnas.1411413111.

10. Diwakarla, S.; Bathgate, R. A. D.; Zhang, X.; Hossain, M. A.; Furness, J. B., Colokinetic effect of an insulinlike peptide 5-related agonist of the RXFP4 receptor. Neurogastroenterol Motil 2020, 32 (5), e13796. doi: $10.1111 /$ nmo.13796.

11. Shabanpoor, F.; Hossain, M. A.; Ryan, P. J.; Belgi, A.; Layfield, S.; Kocan, M.; Zhang, S.; Samuel, C. S.; Gundlach, A. L.; Bathgate, R. A.; Separovic, F.; Wade, J. D., Minimization of human relaxin-3 leading to high-affinity analogues with increased selectivity for relaxin-family peptide 3 receptor (RXFP3) over RXFP1. J Med Chem 2012, 55 (4), 1671-181. doi: 10.1021/jm201505p. 